BBA 26220

\title{
ERYTHROCYTE METABOLISM AND FUNCTION: \\ HEXOKINASE INHIBITION BY 2,3-DIPHOSPHOGLYCERATE AND \\ INTERACTION WITH ATP AND $\mathrm{Mg}^{2+}$
}

\author{
GEORGE J. BREWER
}

Departments of Human Genetics and Medicine (Simpson Memorial Institute), University of Michigan Medical School, Ann Arbor, Mich. 48 Io4 (U.S.A.)

(Received May 28th, 1969)

\section{SUMMARY}

Recent findings have suggested an important role for variation in levels of 2,3-diphosphoglycerate and ATP in the regulation of oxygen transport by the human erythrocyte, and in making homeostatic adjustments to hypoxia. For this reason, the erythrocytic glycolytic mechanisms which control or bring about changes in levels of 2,3-diphosphoglycerate and ATP are of vital importance in understanding respiratory homeostasis. Hexokinase is the first step in glycolysis, and available evidence suggests that it is an important rate-limiting step in the erythrocyte. In this paper we have examined a possible mechanism for feedback control of glycolysis through 2,3-diphosphoglycerate inhibition of hexokinase activity. We have found that 2,3-diphosphoglycerate does inhibit hexokinase and have shown that the inhibition is relieved by increasing concentrations of ATP and $\mathrm{Mg}^{2+}$. It is our conclusion that inhibition of erythrocyte hexokinase by 2,3-diphosphoglycerate, with modulation by ATP and/or $\mathrm{Mg}^{2+}$, is well suited for feedback control of glycolysis, and hence for the control of levels of 2,3-diphosphoglycerate and ATP, which in turn regulate hemoglobin function.

\section{INTRODUCTION}

Recent findings ${ }^{1-8}$ suggest an important role for variation in levels of 2,3 -diphosphoglycerate and ATP in the regulation of oxygen transport by the human erythrocyte, and in making homeostatic adjustments to hypoxia. If such is the case then the glycolytic mechanisms which control or bring about changes in levels of 2,3-diphosphoglycerate and ATP are of considerable importance in respiratory homeostatis. Both 2,3-diphosphoglycerate and ATP are synthesized during glycolysis. Hexokinase is the first, and possibly a rate-limiting step in erythrocyte glycolysis. Dische's early report ${ }^{9}$ that 2,3-diphosphoglycerate is capable of inhibiting hexokinase suggests a possible feedback inhibition mechanism whereby the levels of 2,3-diphosphoglycerate may be a factor in determining rate of glycolysis, and hence levels of 2,3-diphosphoglycerate and/or ATP. However, DEVERDIER AND GARBY ${ }^{10}$ have not 
been able to confirm an effect of 2,3-diphosphoglycerate on hexokinase activity. For these reasons it is the purpose of this paper to explore in vitro the effects of concomitant variation in concentration of three variables, 2,3-diphosphoglycerate, ATP and $\mathrm{Mg}^{2+}$, upon hexokinase activity of human hemolysates.

\section{METHODS}

The basic method of measuring hexokinase activity, using a glucose-6-phosphate dehydrogenase, 6-phosphogluconate dehydrogenase coupled system, was similar to that previously reported ${ }^{11}, 2,3$-Diphosphoglycerate was shown to have no effect on the coupling enzymes in control experiments. We employed a $\mathrm{pH}$ of 7.4 for the assay rather than 8.0 as in previous studies to make conditions more physiological. Concentrations of 2,3-diphosphoglycerate, $\mathrm{ATP}$, and $\mathrm{Mg}^{2+}$ (as $\mathrm{MgCl}_{2}$ ) are indicated in each experiment. 2,3-Diphosphoglycerate was obtained from the sigma Chemical Co., St. Louis, Mo., as the cyclohexylamine salt. Control experiments demonstrated that cyclohexylamine in the molarity employed had no effect on hexokinase activity. In each study of the effect of 2,3-diphosphoglycerate inhibition of hexokinase, a control was performed under exactly the same conditions except that 2,3-diphosphoglycerate was omitted. All results are reported in terms of the percent inhibition, that is the percent loss of activity attributed to the presence of 2,3-diphosphoglycerate in the experimental cuvette.

\section{RESLITS}

The inhibition of hexokinase by varying concentrations of 2,3-diphosphoglycerate is shown in Fig. I at three concentrations of ATP and two concentrations of $\mathrm{Mg}^{2+}$. Increasing 2,3-diphosphoglycerate concentrations causes an increasing inhibition of hexokinase, but the curves become relatively flat at 2,3-diphosphoglycerate concentrations higher than about $25 \cdot \mathrm{IO}^{-4} \mathrm{M}$ 2,3-diphosphoglycerate. Inhibition by 2,3-diphosphoglycerate is increased as the concentrations of ATP and/or $\mathrm{Mg}^{2+}$ are decreased (Fig. I). Of course, as ATP and $\mathrm{Mg}^{2-}$ concentrations are decreased, the absolute en-

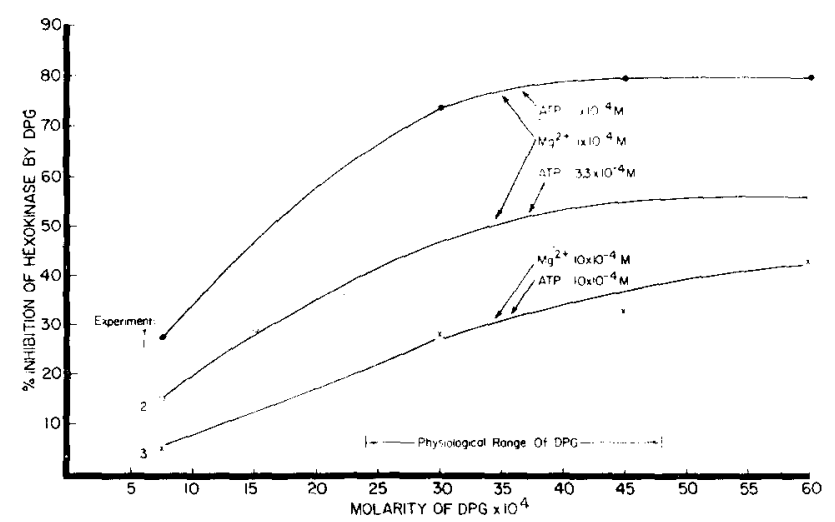

Fig. I. Family of curves showing 2,3-diphosphoglycerate (D)I'(3) inhibition of hexokinase as a function of 2,3 -diphosphoglycerate concentration at three concentrations of $\mathrm{ATP}$ and two of $\mathrm{Mg}^{2} \cdot$. 
zyme activity also decreases. The absolute activity in the control cuvettes (no 2,3-diphosphoglycerate present) under the varying conditions illustrated in Fig. I are shown in Table I, under Expts. I-3. At the lowest concentrations of ATP and $\mathrm{Mg}^{2+}$, hexokinase activity falls to only $\mathrm{I}^{-20} \%$ of its activity at more optimal concentrations of ATP and $\mathrm{Mg}^{2+}$.

\section{TABLE I}

ABSOLUTE ACTIVITY OF ERYTHROCYTE HEXOKINASE UNDER VARYING CONDITIONS IN THE ABSENCE OF 2,3-DIPHOSPHOGLYCERATE

The table is keyed to Figs. I- 3 by Expt. No. Data are means of the number of assays shown in parentheses.

\begin{tabular}{|c|c|c|c|}
\hline $\begin{array}{l}\text { Expt. } \\
\text { No. }\end{array}$ & $\begin{array}{c}A T P \text { concn } \\
\times I 0^{4}(M)\end{array}$ & $\begin{array}{l}M g^{2+} \text { concn } \\
\times I O^{4}(M)\end{array}$ & $\begin{array}{l}\text { Abs. activity } \\
\text { (change in } \\
\left.\text { absorbance }{ }^{\star}\right) \\
\left(60 \text { min at } 23^{\circ}\right)\end{array}$ \\
\hline I & I.O & I.O & 0.024 \\
\hline 2 & $3 \cdot 3$ & I.O & 0.059 (IO) \\
\hline 3 & 10.0 & 10.0 & 0.129 \\
\hline \multirow[t]{5}{*}{4} & 67 & I.O & 0.017 \\
\hline & 6.7 & I.O & $0.06 \mathrm{I}$ \\
\hline & $3 \cdot 3$ & 1.0 & $0.06 \mathrm{I}$ \\
\hline & I. 35 & I.O & 0.029 \\
\hline & 0.67 & I.O & 0.021 \\
\hline \multirow[t]{5}{*}{$5-7$} & 67.0 & 10.0 & 0.091 \\
\hline & 6.7 & 10.0 & 0.142 \\
\hline & $3 \cdot 3$ & IO.0 & 0.097 \\
\hline & I. 35 & IO.O & $0.04 I$ \\
\hline & 0.67 & IO.O & 0.024 \\
\hline \multirow[t]{6}{*}{8,9} & $3 \cdot 3$ & IOO.0 & $0.09 \mathrm{I}$ \\
\hline & $3 \cdot 3$ & 20.0 & 0.076 \\
\hline & $3 \cdot 3$ & IO.O & $0.08 \mathrm{I}$ \\
\hline & $3 \cdot 3$ & 5.0 & $0.07^{8}$ \\
\hline & $3 \cdot 3$ & 2.0 & 0.050 \\
\hline & $3 \cdot 3$ & I.O & $0.05 \mathrm{I}$ \\
\hline \multirow[t]{6}{*}{ Io } & 10.0 & I00.0 & o.I65 (2) \\
\hline & 10.0 & 20.0 & 0.170 \\
\hline & 10.0 & I0.0 & o. 124 \\
\hline & 10.0 & 5.0 & o. I I 7 \\
\hline & 10.0 & 2.0 & 0.054 \\
\hline & 10.0 & 1.0 & $0.044 \quad(2)$ \\
\hline
\end{tabular}

* Measured with a I-cm light path in a Beckman DU spectrophotometer, with a hemoglobir concentration in the cuvette of $0.17 \mathrm{~g} / 100 \mathrm{ml}$.

The family of curves obtained when ATP concentration is varied at three concentrations of 2,3-diphosphoglycerate and two of $\mathrm{Mg}^{2+}$ is shown in Fig. 2. This figure illustrates the dramatic effect of 2,3-diphosphoglycerate inhibition of hexokinase activity as the molarity of ATP falls below $2 \cdot \mathrm{ro}^{-4}$. Once again, the absolute amounts of hexokinase activity in the control cuvettes are shown in Table I under Expts. 4-7.

Similar studies with $\mathrm{Mg}^{2+}$ concentrations as the variable are shown in Fig. 3 at two concentrations of 2,3-diphosphoglycerate and two of ATP. A marked inhibition of hexokinase by 2,3-diphosphoglycerate becomes apparent at low concentrations 
of $\mathrm{Mg}^{2+}$, particularly below $5 \cdot \mathrm{IO}^{-4} \mathrm{M}$. Table I illustrates the absolute amounts of activity in the control cuvettes (Expts. 8-IO).
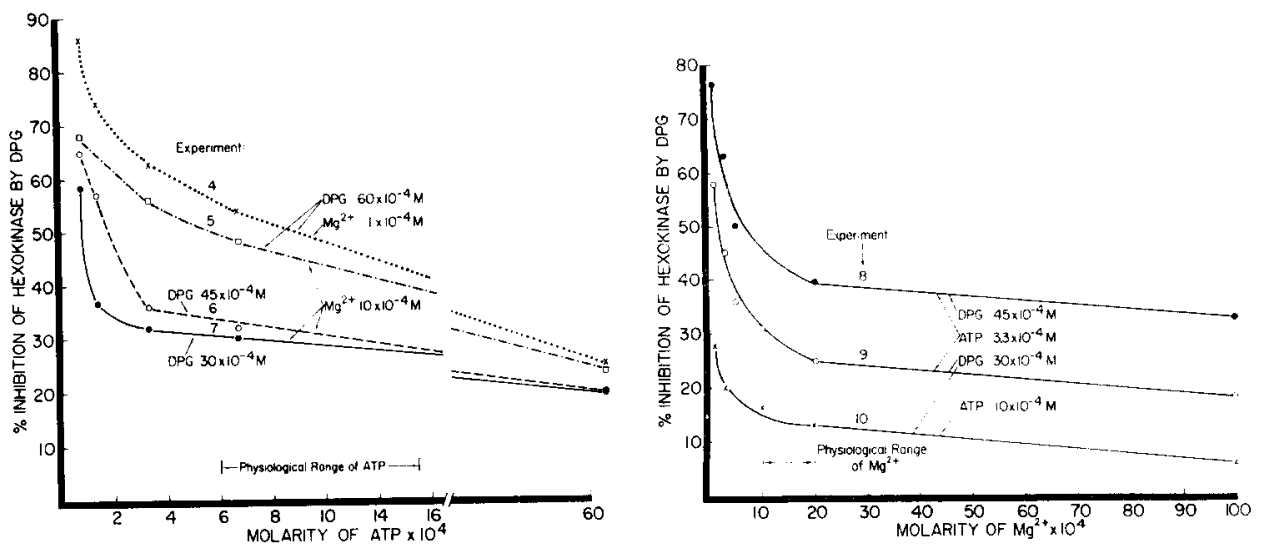

Fig. 2. Family of curves showing 2,3-diphosphoglycerate (1)I'G) inhibition of hexokinase as a function of ATP concentration at three concentrations of 2,3 -cliphosphoglycerate and two of $\mathrm{Mg} \mathrm{g}^{2}$.

Fig. 3. Family of curves showing 2,3-diphosphoglycerate (1)P(i) inhibition of hexokinase as a function of $\mathrm{Mg}^{2+}$ concentration at two concentrations of ATP and two of 2,3 -cliphosphoglycerate.

DISCTSSION

It seems likely that the glycolytic rate of the red cell can under some circumstances be limited by hexokinase activity. The maximal hexokinase activity of hemolysates is lower than that of any other enzyme of glycolysis ${ }^{12}$. In studies of enzyme activities versus glycolytic rates in a series of intact red cells of mammalian organisms, an amazingly good correlation with hexokinase activity was found, considerably better than with other glycolytic enzymes ${ }^{13}$. Hexokinase activity as measured in hemolysates is $3-5$ times greater than in intact cells ${ }^{30,12}$, indicating that hexokinase is in an inhibited state in intact cells. The level of 2,3-diphosphoglycerate is sufficiently high in erythrocytes to make it a likely candidate for this inhibition. With sufficiently low levels of either ATP or $\mathrm{Mg}^{2+}$ through binding or other mechanisms, hexokinase inhibition by 2,3-diphosphoglycerate would become a factor even if it were not otherwise.

In the fully oxygenated cell as it comes from the lung, less of the 2,3-diphosphoglycerate and ATP would be bound by hemoglobin than in the tissues ${ }^{14}$. As the ery throcyte passes through the tissues, the resulting desaturation will result in increased binding of 2,3-diphosphoglycerate by hemoglobin ${ }^{14}$, possibly decreasing inhibition of hexokinase, depending upon ATP and $\mathrm{Mg}^{2+}$ concentration and on the amount of total 2,3-diphosphoglycerate in that particular individual's erythrocytes. The amount of ATP available to hexokinase is critical to its activity (Table I) and critical to the amount of inhibition by 2,3-diphosphoglycerate (Fig. 2). Some proportion of the ATP molecules will presumably be bound to deoxyhemoglobin as the cell loses oxygen in the tissues, and, in addition some ATP will be bound to various enzymes. A question of considerable importance, then, is the relative binding of ATP versus 2,3-diphosphoglycerate to hemoglobin. 
Similar considerations hold for $\mathrm{Mg}^{2+}$. At low concentrations of free $\mathrm{Mg}^{2+}$ inhibition of hexokinase by 2,3-diphosphoglycerate is severe (Fig. 3). As the concentration of $\mathrm{Mg}^{2+}$ is increased the inhibition of hexokinase by 2,3-diphosphoglycerate is relieved even at fairly low ATP concentrations. The physiological range of total $\mathrm{Mg}^{2+}$ within the red cell is shown in Fig. 3. However, current evidence indicates only about $5 \%$ of the $\mathrm{Mg}^{2+}$ in the red cell is unbound ${ }^{15-17}$, placing the free $\mathrm{Mg}^{2+}$ level on the steep portion of the 2,3-diphosphoglycerate-hexokinase inhibition curve, and suggesting $\mathrm{Mg}^{2+}$ as a possible important regulator of red cell metabolism.

The probable explanation for the failure of DEVERDIER AND GARBY ${ }^{10}$ to find 2,3-diphosphoglycerate inhibition of hexokinase may involve the use of high concentrations of $\mathrm{Mg}^{2+}$, and to a lesser extent ATP, in their incubations. As shown here, 2,3-diphosphoglycerate inhibition of hexokinase is profoundly relieved by increasing concentrations of these two substances.

It seems clear that the mammalian red cell is organized in a complex manner in order to perform its vital function of gas transport. It is becoming apparent that the metabolism of the cell is intimately involved with hemoglobin function. 2,3-Diphosphoglycerate and ATP seem to be vital links in this respect, both in modifying the oxygen affinity of hemoglobin and in affecting glycolysis. Inhibition of hexokinase by 2,3 -diphosphoglycerate with modulation by ATP and/or $\mathrm{Mg}^{2+}$, seems ideally suited for feedback control of glycolysis and hence of the level of 2,3-diphosphoglycerate and ATP, which in turn regulate hemoglobin function.

\section{ACKNOWLEDGMENTS}

The excellent technical assistance of $\mathrm{Mr}$. D. Patel in these studies is acknowledged. Helpful conversations with Dr. J. W. Eaton are also gratefully acknowledged.

This work was supported in part by U.S. Public Health Service Grant AM 0938I and Career Development Award AM 07959 and in part by Contract DADAI7-69-C9I03 with the U.S. Army and Navy Medical Research and Development Commands.

\section{REFERENCES}

I A. Chanutin and R. R. Curnish, Arch. Biochem. Biophys., I2 I (I967) 96.

2 R. Benesch, R. E. Benesch and C. D. YU, Proc. Natl. Acad. Sci. U.S., 59 (1968) 53 I.

3 R. Benesch and R. E. Benesch, Biochem. Biophys. Res. Commun., 26 (1967) I62.

4 J. W. Eaton and G. J. Brewer, Proc. Natl. Acad. Sci. U.S., 6I (1968) 756.

5 J. W. Eaton, G. J. Brewer and R. F. Grover, J. Lab. Clin. Med., 73 (1969) 603.

6 C. Lenfant, J. Torrance, E. English, C. A. Finch, C. Reynfarje, J. Ramos and J. Faura, J. Clin. Invest., 47 (I968) 2652.

7 J. W. Eaton and G. J. Brewer, Clin. Res., I6 (I968) 454

8 G. J. Brewer and J. W. Eaton, J. Clin. Invest., 78 (1969) II9.

9 Z. Dische, Bull. Soc. Chim. Biol., 23 (I94I) I I 40.

ro C.-H. DeVerdier and L. Garby, Scand.J. Haematol., 2 (1965) 305.

i G. J. Brewer, R. D. Powell, S. H. Swanson and A. S. Alving, J. Lab. Clin. Med., 64 (1964) 601 .

i2 R. G. Chapman, M. A. Hennessey, A. M. Waltersdorph, F. N. Huennekens and B. W. GABRIO, J. Clin. Invest., $4 \mathrm{I}$ (I962) I 249.

I 3 G. JaCOBASCH, Folia Haematol., 89 (1968) 376.

if A. Chanutin and E. Hermann, Arch. Biochem. Biophys., I3I (1969) I80.

I5 T. A. Rogers, J. Cellular Comp. Physiol., 57 (I96I) I I9.

I6 L. Garby and L. Thoren, Scand. J. Clin. Lab. Invest., I 4 (1962) 392.

I7 I. A. Rose, Proc. Natl. Acad. Sci. U.S., 6I (I968) 1079. 